\title{
Reflexiones en torno a los viajes de A. J. Cavanilles por tierras de Valencia (1791-1793)
}

\author{
A. GONZÁlez BuENo
}

\begin{abstract}
«... le somos deudores con particularidad los $q^{e}$. vivimos en este delicioso suelo, y estamos obligados á contribuir á una obra $q^{e}$. acredita la nación española, y manifiesta el carácter valenciano, $q^{e}$. (...) debía ser imitado para la prosperidad de $n^{\text {tra }}$. península."
\end{abstract}

Lorenzo, obispo de Segorbe, a A.J. Cavanilles. Segorbe, 12-IV-1796. (Arch. R.J.B., XIII,7,4,53).

El 20 de marzo de 1792 fue martes, el cielo debía estar nublado pero nada hacía pronosticar que amenazara tormenta. En Moncada, un hombre de 47 años, esbelto, de fisonomía agraciada, acicalado en su pelo y sus ropas más de lo aconsejable para las tareas del campo, se dispone a iniciar una excursión por el Camp de Morvedre.

Su nombre es Antonio José de Cavanilles, y está aquí por expreso deseo de S.M. Carlos IV; una R.O., expedida en 1791, le encomienda recorrer el territorio peninsular con objeto de escribir una "Historia Natural de España". ¿Una misión de carácter científico o un momentáneo exilio? Un año antes se le había concedido igual comisión a Gaspar Melchor de Jovellanos; éste principiaría por Asturias, su tierra; A.J. Cavanilles haría lo propio con la suya, Valencia ${ }^{1}$.

\footnotetext{
1 Una relación, la más completa de las disponibles, de los estudios sobre A.J. Cavanilles, puede consultarse en J.M. LóPez Piñero y M.L. LÓPEZ TerradA (1983). "Antonio José de Cavanilles (1745-1804). Estudio bibliográfico». En: Cavanilles. Naturalista de la Ilustración. 1745-1804: 51-80. Madrid.
} 


\section{A. GONZALEZ BUENO}

¿Cuántos informes sobre la Historia Natural de su Reino necesita este monarca? Desde luego A.J. Cavanilles es una persona incómoda para algunas camarillas de la Corte; tiene pretensiones sobre la dirección del Real Jardín ${ }^{2}$, y su antagonista, Casimiro Gómez Ortega, está dispuesto a desplegar toda sus fuerzas cortesanas, que no son pocas, para evitarlo. Nuestro protagonista acaba de llegar a España y, aunque ducho en intrigas y polémicas, y bien informado de los asuntos de la Corte, aún es neófito en la política de los cafés y las tertulias, donde.C. Gómez Ortega sabe desenvolverse con una habilidad pasmosa ${ }^{3}$.

A.J. Cavanilles acaba de llegar de París, lo ha hecho a finales del otoño de 1789, porque la situación social que se vive en Francia, tras los incidentes de ese verano, hacía incómoda su presencia y la de sus valedores, los Duques del Infantado, de cuya Casa es capellán y preceptor de sus hijos:

«Las persecuciones que experimenta todo hombre, mayormente los ricos, y sobre todo los clérigos, me obligó a zafarme, oculto y disfrazado, y forzó a los Señores a abandonar aquella ciudad.» ${ }^{4}$

escribirá a su entrañable amigo José Viera y Clavijo, quizás su más fiel rodrigón. El comunicado de tal decisión al Conde de Floridablanca, de quien ya ha recibido apoyo en otras ocasiones, parece menos dramático:

«... para evitar el imbierno, saldré quanto antes de aquí, y apenas llegue, procuraré tener el honor de presentarme á V.E. . ${ }^{5}$

y es que nuestro protagonista tiene un excelente disposición para la carrera política, sabe distribuir los elogios y cuidar las formas, el atildamiento de su aspecto externo es fiel reflejo de su carácter; A.J. Cavanilles ha escrito a Floridablanca el 29 de septiembre: hacía sólo ocho días (21-IX) que Floridablanca había encargado a la Inquisición la defensa ideológica frente a la Revolución francesa; nuestro protagonista aún no lo sabe, por eso justifica su vuelta a España «para evitar el imbierno».

\footnotetext{
2 Así parece explicarse el comentario de la carta dirigida por A.J. Cavanilles a J. Viera y Clavijo, desde París, el 8-IX-1789. (Cf. Antonio José Cavanilles (1981). Cartas a José Viera y Clavijo. Introducción y notas de Alejandro Cioranescu. Santa Cruz de Tenerife, p. 120).

${ }^{3}$ Sobre C. Gómez Ortega puede consultarse F.J. Puerto Sarmiento (1992). Ciencia de Cámara. Casimiro Gómez Ortega (1741-1818) el científico cortesano. Madrid.

${ }^{4}$ Carta de A.J. Cavanilles a J. Viera y Clavijo, Madrid, 25-XI-1789 (reproducida en op. cit. nota 2, p. 121).

${ }^{5}$ Carta de A.J. Cavanilles al Conde de Floridablanca. París, 29-IX-1789 (Archivo Histórico Nacional -A.H.N.-, Estado, leg: 3022,7).
} 


\section{REFLEXIONES EN TORNO A LOS VIAJES DE A.J. CAVANILLES}

Me he querido detener en este detalle, vanal en apariencia, porque define muy bien, a mi juicio, el carácter de A.J. Cavanilles; en sus textos, los que nos han llegado, tante en los inéditos como los que fueron publicados, no suelen encontrarse contradicciones en lo que se refiere a su pensamiento, pero son enigmáticos hasta el extremo, nos dejan conocer sombras de una figura, una silueta cuyo rostro apenas se deja vislumbrar, sólo en las cartas a sus amigos, a las personas de mucha confianza, o en sus diarios para uso privado se nos muestra algo más relajado en sus expresiones, algo más espontáneo, siempre dentro de unos límites de autocontrol que resultan, a todas luces, excesivos:

"Quando tenga el honor de ver a V.E., [escribe a la Duquesa del Infantado] le diré cosas bien extrañas de Alberique, no quiero fiarlas al papel, pero son de mucho bulto..." ${ }^{6}$.

¡Cómo contrasta este cuidado, en no escribir lo que pudiera ser inoportuno, con el afán polemista que quiso dar a sus escritos científicos; desde la, tantas veces comentada, reivindicación de la ciencia española frente a los escritos de Nicholas Masson de Morvilliers, hasta las controversias botánicas con Friedrich Kasimir Medikus o Charles B. de L'Heritier, o. las más virulentas contra sus oponentes españoles, C. Gómez Ortega y su escuela!?.

¿A qué este esmero por cuidar sus expresiones? Parece responder a un deseo asumido de proteger su imagen en la dura arena de la Corte; poco sabemos de sus primeros años de vida, y los datos disponibles, muy escasos, le sitúan en una familia acomodada, nacido de un padre ya anciano, y bajo el cuidado de un único hermano treinta y siete años mayor que él. Quizás esta especial situación familiar sea la responsable de su carácter, petulante, sagaz, adulador, trabajador infatigable y constante en el logro de sus objetivos ${ }^{8}$. En febrero de 1796, escribiría al Príncipe de la Paz en los siguientes términos:

"Ya van dos años desde que V.E. se dignó aprobar mi pretensión á favor de mi hermano, pasando varias recomendaciones a gracia y justicia. Se han verificado muchas vacantes sin recaer ninguna en mi hermano Josef, ahora hay dos, y pudiendo V.E. hacer por si que recayga á mi favor la gracia, le rue-

\footnotetext{
${ }^{6}$ Carta de A.J. Cavanilles a la Duquesa del Infantado. Valencia, 4-V-1793 (A.H.N., Osuna, Cartas, leg: 615,31).

${ }^{7}$ De ellas se han ocupado, entre otros, L. Gutiérrez Colomer (1947), «Aspectos poco conocidos de la vida de un botánico español: Antonio Joseph Cavanilles». Anales de la Real Academia de Farmacia, 13: 48-64. Madrid, y F. Pelayo y R. Garilleti (1992) «La formación y actividades botánicas de A.J. Cavanilles». Asclepio, 44(2): 129-154. Madrid.

${ }^{8}$ Seguimos la genealogía establecida por el Marqués de Jaureguizar [F.J. PÉREZ DE RADA y Díaz RuBín] (1971). Relación de los poseedores del Castro y Palacio de Prioranza del Bierzo, de alguno de sus allegados y descendientes de ellos. Madrid.
} 


\section{A. GONZALEZ BUENO}

go se digne hacerlo (...) Quando no hubiese vacante podria V.E. nombrarlo supernumerario de alguna Audiencia...." 9 .

Antes de que transcurriera un mes Josef Tomás Cavanilles engrosaría el cuerpo de los funcionarios al servicio de la Corona ${ }^{10}$.

A.J. Cavanilles no parece querer permitirse un solo desliz en su carrera, su más seguro valedor, su único apoyo seguro, son sus escritos; él lo sabe, y los cuida y los mima hasta el exceso, prepara él mismo los dibujos, controla a los grabadores, elige los mejores impresores, y nos ofrece unos textos botánicos con un latín cuajado de hipérbaton y, a la vez, de una precisión científica envidiable. El lo sabe, sus escritos son las armas de su triunfo:

«V.E. sabe conocer el mérito y recompensarme si en mis obras ya publicadas y en lo que he recogido para esta historia natural hubiera alguno. Espero que V.E. querrá se me concedan los honores a los que aspiro.."11

escribía al Duque de la Alcudia en el verano de 1793, y no es mero saludo protocolario, como hemos visto.

Mas volvamos al objeto de nuestro interés principal; líneas arriba comentaba la feliz coincidencia de dos viajes próximos en el tiempo, el de G.M. Jovellanos y éste que nos ocupa. Los escritos que nos han llegado de ambos tienen un común sistema de trabajo, en palabras de Jovellanos:

«Mi método se ha reducido hasta aquí a observar cuanto puedo, según la rapidez de mis correrías, y a exponer a usted mi modo de pensar (...) y si alguna vez alabo o vitupero, es solo cuando la vista del bien o el mal hacen que el corazón gobierne la pluma y le dicte sus sentimientos.»12

Y es que esta capacidad tan clara para discernir entre el bien y el mal es innata al hombre ilustrado, que sabe encontrar, a través de la descripción exacta de los rasgos físicos y psíquicos de un pueblo, las necesarias consecuencias de índole social o económico. A.J. Cavanilles se expresará en términos muy parecidos:

\footnotetext{
${ }^{9}$ Carta de A.J. Cavanilles al Príncipe de la Paz. Madrid, 21-II-1796 (A.H.N., Estado, leg: $3022,7)$.

10 Joseph Tomás Cavanilles y Mas (1767-1844), hijo de su hermano José Cavanilles y Llosano (1708-1772) y de Eulalia Mas y Damiá (1738-1819); su sobrino por tanto, mas en sus escritos, y con probabilidad en vida, A.J. Cavanilles prefería dirigirse a él como hermano.

11 Carta de A.J. Cavanilles al Duque de Alcudia. Valencia, 16-VII-1793 (A.H.N., Estado, leg: 3022,7$)$.

12 El texto en la "Carta novena» de G.M. Jovellanos a Antonio Ponz (cf. vol. 2, p. 47 de las Cartas del Viaje por Asturias, en la edición de J.M. Caso González. Gijón, 1981).
} 


\title{
REFLEXIONES EN TORNO A LOS VIAJES DE A.J. CAVANILLES
}

\author{
«El único termómetro para graduar las licencias ó las prescripciones ha \\ de ser el bien ó el mal de la especie humana.»13
}

La descripción del viaje de A.J. Cavanilles, como las Cartas del viaje de Jovellanos, son sendos programas reformistas, muy próximos en algunas de sus formulaciones; programas que ofrecen soluciones, distintas según la idiosincrasia local, pero centradas ambas en esa mítica búsqueda de "la felicidad del pueblo».

$\mathrm{Y}$ a establecer las medidas que deben adoptarse, en las distintas tierras de Valencia, para lograr ese mayor «estado de felicidad», dedicará A.J. Cavanilles sus esfuerzos. Sus «Observaciones sobre el Reino de Valencia», el resultado de esos tres años de peregrinar por estas tierras, son ejemplo paradigmático de lo que, un ilustrado de la España de finales del XVIII, ve y siente al atravesar los terrenos que le son queridos. Su viaje, como el de G.M. Jovellanos, no reúne las características de un periplo expedicionario, aun cuando tenga algo en común con ellos, no recorrerá los caminos solo, irá acompañado de sus amigos, o los hará nuevos entre aquellos que mantengan sus mismos ideales acerca del fomento de la agricultura y la felicidad pública.

Luego habremos de adentrarnos en el itinerario en sí, al menos de los viajes que se conservan en sus cuadernos de campo ${ }^{14}$; hagámoslo ahora en el pensamiento del viajero, en lo que a sus preocupaciones sociales respecta, un campo éste en que A.J. Cavanilles, aún sin llegar a la vehemencia de Cabarrús, a quien, por cierto, no parece tener en mucha estima, sabrá expresarse con meridiana claridad.

La organización social y económica del Antiguo Régimen es cuestionada a lo largo de todo su viaje; como el G.M. Jovellanos del "Informe en el expediente de la Ley Agraria», A.J. Cavanilles mantendrá que la reforma debe empezar por aumentar la «felicidad» del campesino, su crítica contra los terratenientes e intermediarios es feroz, y de ella no están exentas las comunidades religiosas, pese al estado a que se acoge nuestro personaje. Pero no es a los campesinos a los que A.J. Cavanilles dirigirá sus enseñanzas, sino a aquellos propietarios que procuran las mejoras necesarias en sus tierras. Y en sus «Observaciones...» irá desgranando el nombre de estos hacendados, con-

\footnotetext{
13 A.J. CAVANILles (1795), Observaciones sobre la Historia Natural, Geografía, Agricultura, Población y Frutos del Reyno de Valencia. Madrid, (vol. 1, p. 173).

${ }^{14}$ Utilizamos los manuscritos depositados en el Archivo del Real Jardín Botánico de Madrid (A.R.J.B.): Diario de las excursiones del viaje a Valencia, 20-III-1792 / 17-VIII-1792 (leg: XIII,7,1); Diario de las excursiones del viaje a Valencia, 16-IV-1793 / 3-X-1793 (leg: XIII,7,2); además de las notas, apuntes e informes anejos a los volúmenes publicados de las "Observaciones...» (legs: XIII,7,3 / XIII,7,6). Conste aquí mi agradecimiento a P. San Pío Aladrén y P. Collar por las facilidades dadas para la consulta del material custodiado en el archivo del Real Jardín de Madrid.
} 
formando una lista de personas ejemplares, de modelos a imitar, por toda la geografía valenciana; no habremos de detenernos en rehacer la nómina, pero fijémonos en la caracterización de "ciudadanos instruidos» con que suele definirles, porque ésta será una de las opciones finales por las que aboga A.J. Cavanilles, hasta el extremo de plantearse la utilidad de su periplo como solución imperfecta ante esta carencia:

«El que viaja con instrucción y cuidado, puede descubrir algunas cosas, pero los que están establecidos en los pueblos, son los únicos que pueden completar los conocimientos útiles á las ciencias y al estado.» ${ }^{15}$

Y como maestro obra, dando instrucciones sobre el modo de podar los olivos o los algarrobos, de injertar los frutales, de construir presas, de potenciar el comercio, o sobre la necesidad de reformar un camino.... Es un misionero de la ilustración, y como buen evangelista se esfuerza en que su doctrina llegue a quienes están en posición de llevarla a la práctica:

"Algunos ricos propietarios salieron conmigo al campo, oyeron al pie del árbol estas reflexiones, y me prometieron ponerlas en práctica, y animar á los otros con su exemplo.» ${ }^{16}$

A.J. Cavanilles cuenta con pocos medios materiales para elaborar las «Observaciones...» de sus viajes por tierras valencianas; le acompaña la «Historia del reyno de Valencia» que escribiera Gaspar Escolano, a ella hará alusión repetidas veces a lo largo del texto, en especial cuando se ocupe de las producciones o de la población de estas tierras; conoce, y en ocasiones critica, las explicaciones del «Viage por los Alpes» de Horacio Benito de Saussure, a quien tiene presente en sus opiniones sobre la configuración de los terrenos y el origen de las fuentes de agua, y a quien sigue en el modelo a utilizar para dibujar los relieves (los cerros de perfil y sombreados de poniente); para las interpretaciones orogenéticas y la presencia de fósiles sigue al abàte Olivi que, en estos momentos, publica su «Zoología Adriática...» (Bassano, 1792); por supuesto conoce a los escritores fisiócratas franceses, a los que cita y sigue en sus consideraciones, los textos del abate Rozier, los métodos de molienda de Sieuve, o los del abate Tessier para mejorar la sementera son comentados en sus escritos; también conoce la «Introducción a la Historia Natural y a la Geografía Física de España» que había publicado

15 A.J. Cavanilles (1795), Observaciones sobre la Historia Natural, Geografía, Agricultura, Población y Frutos del Reyno de Valencia. Madrid (vol. 1, p. 4).

16 A.J. Cavanilles (1795), Observaciones sobre la Historia Natural, Geografía, Agricultura, Población y Frutos del Reyno de Valencia. Madrid (vol. 1, p. 44). 
Guillermo Bowles (Madrid, 1775), pero su opinión sobre esta obra no es positiva.

Para la construcción de mapas dice valerse sólo de una brújula; conoce el mapa levantado por Tomás López de Vargas, «López» sin más en las menciones que de él hace en sus diarios manuscritos, siempre con ánimo de corregirlo; su crítica hacia esta obra es feroz:

«... ya nos responde el en su advertencia al lector, en donde confiesa que nada ha visto y $\mathrm{q}^{\mathrm{e}}$. trazó las distancias, los montes y los ríos, por las relaciones que le han comunicado. Tales serán también las noticias que recibió por lo perteneciente a las distancias (...), C'est une excellente maniere de tromper le public en lui tirant l'argent de la poche!.»17;

por supuesto esta opinión nunca fue llevada a imprenta.

Para las costas emplea la carta marítima de Tofiño, al que menciona y corrige en alguna ocasión. El resto del instrumental necesario lo suple con ingenio, véase un ejemplo:

\begin{abstract}
«... aunque privado de instrumentos recurrí al medio de dexar caer un fuerte canto, contando las pulsaciones que empleaba en llegar al primer descanso. Ocho veces batió mi arteria mientras que el canto baxaba hasta dicho sitio sin desviarse de la perpendicular; y si se regula la pulsación por un minuto segundo, tendremos, según las leyes, que los cuerpos observan en su descenso libre, 960 pies de altura perpendicular desde lo mas alto hasta el primer descanso; y siendo esta la mitad solamente, resultarían 1920 pies de altura total en aquel sitio.» ${ }^{18}$
\end{abstract}

La medición no parece del todo certera, pero el método es harto ingenioso.

Nuestro protagonista camina a pie o a lomos de caballería, rara vez solo aun cuando sus "Observaciones...» impresas parezcan indicar lo contrario; su equipaje lo carga a lomos de una mula que, no pocas veces, le hizo sufrir alguna mala pasada.

Mas dejamos a A.J. Cavanilles en las puertas de Moncada: hora es que volvamos a encontrarnos con él; allí se había hospedado en casa de Francisco Espinosa, médico del lugar, que le acompañará en la primera expedición de la que nos queda noticia en sus diarios, la realizada el 20 de marzo de 1792 al jardín de Puçol; allí se entrevistó con el Padre Constantino, un capuchino al que previamente había puesto sobre aviso de la visita el Arzo-

\footnotetext{
17 A.J. Cavanilles, Diario de excursiones... [1-X-1792]. (A.R.J.B., leg: XII, 7,1, fol. 138).

18 A.J. Cavanilles (1795), Observaciones sobre la Historia Natural, Geografía, Agricultura, Población y Frutos del Reyno de Valencia. Madrid (vol. 1, p. 20).
} 
bispo de Valencia. Poco avanzada estaba aún la estación para que el jardín pudiera ofrecer algún interés, y A.J. Cavanilles decide proseguir su camino hacia Morvedre, donde habría de llegar esa misma noche; emplearía el día siguiente en recorrer los cerros de alrededor y en dibujar la soberbia vista del castillo que habría de grabar luego Tomás López Enguídanos; esa misma tarde emprendería camino hacia Almenara, allí examinó la fuente de Quart de les Valls y recogió algunas notas sobre el cultivo del algarrobo y las minas de hierro ubicadas en Gilet:

«Aquí empecé a sentir con vehemencia el dolor que ocho días hace experimenté por primera vez y que los facultativos graduaron de flato: me incomodó sobremanera hasta que después de dos horas y haber llegado à la posada, con el socorro de beber agua caliente empezó a disminuyr y cesó en fin: por esto (...) mude de dictamen para ver lo que los facultativos de Valencia me dirían para prevenir.» 19

Abandona sus primitivas intenciones y vuelve sobre sus pasos camino a Valencia; el día 24 atraviesa Museros, donde tiene noticia de su antiguo amigo, el P. Joseph Muñoz «à quien 32 años de ausencia borraron la fisonomía que conservaba.»

Entró en Valencia esa misma noche, mas pronto habría de recuperarse y emprender de nuevo viaje, esta vez en compañía de ése, su antiguo amigo, con quien visita los conventos próximos a Museros entre el 31 de marzo y el 2 de abril; desde aquí se dirigirá a las canteras de donde se extrajo el mármol para construir el altar de San Vicente de Valencia, ahora en compañía del dominico fray Joseph Romero; al día siguiente, y con el propósito de conocer la zona de origen del alabastro con que está construida la puerta del palacio del Marqués de Dos Aguas, emprende viaje hacia Picassent, analizará el material, ayudado por Tomás Villanova, pero también tendrá ojos para observar la dura situación laboral de quienes trabajan:

«Me contaron que suceden desgracias, por caer sobre los trabajadores trozos que les estropean o matan; y esto porque el propietario ó arrendador para ganar mas, difiere mas de lo que debe el desmontar de la espesa capa de tierra el trozo que se debe barrenar. En esto debía velar la justicia y contener con penas la codicia de los que atropellan la humanidad. ${ }^{20}$

La ira debió agudizar el dolor del viajero:

19 A.J. CaVAnilles, Diario de excursiones... [23-III-1792]. (A.R.J.B., leg: XIII,7,1, fol. 6).

20 A.J. Cavanilles, Diario de excursiones... [3-IV-1792]. (A.R.J.B., leg: XIII,7,1, fol. 11). 


\title{
REFLEXIONES EN TORNO A LOS VIAJES DE A.J. CAVANILLES
}

\begin{abstract}
«Al volver ese día á casa me atacó de nuevo el dolor de hijada, molestándome por espacio de 15 horas: me causó vómitos por tres veces de lo que había comido diez y doce horas antes, ni quiso ceder a varias lavativas, mucho aceyte y diez grandes tazas de agua caliente. Pasé malísima la noche del 3 al 4 y no me tranquilicé hasta las once horas de la mañana de este ultimo día. Me quede en cama y á dieta rigurosa dos días y el Viernes Santo salí de casa, aunque débil." 21
\end{abstract}

Así acaba la primera excursión, pero pronto habría de reiniciar sus andanzas; el 9 de abril emprende una segunda expedición que habría de resultar especialmente fructífera; principia por las tierras de la Baronía de Alberíc, donde se detiene a analizar los depósitos de yeso del puerto de Càrcer, pasará luego a Llosa de Ranes, herborizará El Puig, cuya flora estudia con especial cuidado, y dirige sus pasos hacia la "tan ponderada» fuente de Bellús. Desde aquí torna hacia la Vall d'Albaida:

«Un terreno tan hermoso y fértil no puede menos de influir en el carácter de los naturales, los que hallé sumamente atentos, de trato amable y dispuestos siempre a comunicar quantas noticias convenían...”22.

En el examen de este valle y sus gentes se ocupa el 15 y 16 de abril; el siguiente día, en compañía de un grupo de amigos (Vicente Navarro, Jaime Ferrandis, José Plá y José Gandía «boticario del lugar muy instruido en farmacia y botánica») se encamina hacia Adzaneta de Albaida:

«Pocos lugares habrá en España que hayan declarado al ocio mayor guerra, y pocos también en donde logren mejor suerte los vecinos (...) Que aumento de riquezas para una población corta! (...) ${ }^{23}$

y ante el entusiasmo producido en su corazón de ilustrado, no duda en generalizar:

«Agricultura, y fabricas son los dos exes de la felicidad y de la virtud cívica.» ${ }^{24}$

Apenas come, extasiado ante la fertilidad de las tierras de este Marquesado, ni siquiera la lluvia le disuade de ascender al monte de Santa Ana:

\footnotetext{
21 A.J. Cavanilles, Diario de excursiones... [3-IV-1792]. (A.R.J.B., leg: XIII,7,1, fol. 11).

22 A.J. Cavanilles, Diario de excursiones... [14-IV-1792]. (A.R.J.B., leg: XIII,7,1, fol. 18v).

23 A.J. CavanILles, Diario de excursiones... [17-IV-1792]. (A.R.J.B., leg: XIII,7,1, fol. 19).

24 A.J. CAVANILles, Diario de excursiones... [17-IV-1792]. (A.R.J.B., leg: XIII,7,1, fol. 19).
} 


\title{
A. GONZALEZ BUENO
}

\begin{abstract}
«En fin era tal la delicia del sitio por la abundancia de plantas, que solamente la noche que amenazaba me pudo arrancar de allí para bajar.» ${ }^{25}$
\end{abstract}

Gran parte del día siguiente, el 18 de abril, hubo de ser dedicada a arreglar plantas y a dibujar las novedades observadas; tras esta necesaria reordenación de sus materiales, retoma su ruta hacia Ontinyent, un terreno que le asombra aún más que las tierras ya visitadas de la Vall d'Albaida.

"En ninguna parte del Reyno si exceptuamos la capital hay tanta nobleza, cuyo trato llano y sin ceremonia hace agradable la mansión que allí hace el que viaja. ${ }^{26}$

Nuestro clérigo se encuentra a gusto en estas tierras, ese trato con la nobleza siempre le ha gustado, y en Ontinyent se siente como en casa; en la versión definitiva, la que enviará a la imprenta, se mostrará más comedido en sus apreciaciones, pero en sus diarios son todo parabienes, una adulación excesiva que el propio abate sabrá corregir.

Explorará el resto del valle de Biar, prestando una atención extremada a sus mármoles, quizás por deseo expreso de la Duquesa del Infantado, muy interesada en estas producciones ${ }^{27}$; visitará Bocairent, del que nos ha legado una idílica vista y una minuciosa descripción del trabajo de los alfareros de la zona; Bañeres, con otra visión no menos idílica y un detallado estudio sobre el modo de injertar los pinos y alguna alusión a las fiestas de moros y cristianos, por cierto no muy de su agrado; el centro de todas estas excursiones será Ontinyent: no parece que A.J. Cavanilles tuviera prisa por alejarse de la villa. No hay duda que el viajero se encuentra a su gusto, ha conocido a los propietarios de las grandes heredades del valle, y con ellos visita sus haciendas; Bartolomé García, Francisco Sirera o José Castelló, son nombres que habrán de perdurar en su memoria y en sus escritos.

Mas el periplo debe continuar; pese a la insistencia de la lluvia, emprende camino a Castalla; allí trabará contacto con Tomás Rico,

"hombre que sabe juntar una fortuna considerable con un cuidado muy particular á la agricultura (...) me suministró noticias interesantes, pasamos así la tarde y gran parte de la noche, y en esta experimenté de nuevo el dolor

\footnotetext{
25 A.J. CaVANILles, Diario de excursiones... [17-IV-1792]. (A.R.J.B., leg: XIII,7,1, fol. 20).

26 A.J. CAVANILles, Diario de excursiones... [20-IV-1792]. (A.R.J.B., leg: XIII,7,1, fol. 23)

27 Sobre la elección y compra de tableros de mármol versa la correspondencia mantenida entre A.J. Cavanilles y la Duquesa del Infantado durante el mayo de 1793 (cf. A.H.N., Osuna, Cartas, leg: 615,31).
} 
que me afligió en otras ocasiones. Lo atribuí al haberme mojado y no haber tenido la precaución de mudarme ni secar la ropa.... ${ }^{28}$

Las inclemencias del tiempo, que continuaron durante algunos días, y la buena conversación con Tomás Rico y sus amigos, le hacen pasar un par. de días en Castalla; no está inactivo, recorre las proximidades de la villa, pero dedica a la charla instructiva más tiempo del que nos tiene acostumbrados. Aún con lluvia, se decidirá a proseguir el viaje hacia Onil e Ibi; el cuidado con que es trabajada esta vega, en especial el cultivo del almendro, causan su admiración:

«... salí á pisar lo que de lejos admiraba, y redobló el gusto y el deleyte mientras duraba el camino desde Castalla hasta Onil (...) y aunque el viento soplaba con violencia hasta incomodar al mas duro, lo hice con satisfacción (...) el terreno de Onil y aun de toda la hoya es superior á todos ó los que lo cultivan merecen el primer titulo en la agricultura.» ${ }^{29}$

El término de Ibi le parece menos cuidado, el camino al pantano de Tibi le produce espanto:

«El terreno, por espacio de dos horas es el mas á propósito para que los malvados practiquen sus ideas: barrancos á cada paso y en estos, canales capaces de ocultar centenares de hombres. Aun se ve junto al camino la mano del asesino que mató a un infeliz.... ${ }^{30}$;

la presa le asombra, «... obra digna de un pueblo rico é industrioso...»: de ella nos legará un dibujo interpretativo.

La excursión prosigue hacia tierras de Xixona. Allí, en contraste con las de Ibi y Tibi, encuentra tierras incultas, en demasía para su espíritu de fisiócrata, que le inducen a calificar a los habitantes de Xixona «... son mas cultivadores de jardines, que grandes labradores.... ${ }^{31}$

Herboriza la Serra de Cabesó d'Or y realiza sus acostumbradas observaciones geográficas, esta vez en compañía de Francisco Ignacio Soler, en cuya casa se hospeda durante su estancia en Xixona.

El cuatro de mayo retorna a Ibi. En su camino estudia la vegetación de la Serra de la Carrasqueta; en Ibi descansa y dialoga con José Alcaraz sobre el modo de injertar las encinas y las parras; al día siguiente vuelve a ponerse en

${ }^{28}$ A.J. CAVANILles, Diario de excursiones... [25-IV-1792]. (A.R.J.B., leg: XIII,7,1, fol. 27v).

${ }^{29}$ A.J. CaVANILleS, Diario de excursiones... [27-IV-1792]. (A.R.J.B., leg: XIII,7,1, fol. 28v).

30 A.J. CAVANILles, Diario de excursiones... [30-IV-1792]. (A.R.J.B., leg: XIII,7,1, fol. 31v).

31 A.J. Cavanilles, Diario de excursiones... [3-V-1792]. (A.R.J.B., leg: XIII,7,1, fol. 34). 
camino, ahora con destino a Alcoi. Las tierras de Alcoi, bien trabajadas, vuelven a ser de su agrado, recorre los cursos de los ríos que confluyen en Alcoi, en compañía de José Chisbert y José Descals, sus contertulios durante las noches pasadas en esta localidad, con ellos examina las canteras de mármol blanco; con todo, los terrenos no producen cuanto debieran:

\footnotetext{
«Falta no obstante á los de Alcoy y ellos lo conocen, ver el acopio de maquinas que tiene los ingleses y franceses: (...) para esto convendría infinito que algunos de los mas instruidos viajaran y se establecieran por algún tiempo en Londres y otras partes; del mismo modo que se han pensionado á tantos para que se instruyan en matemáticas, medicina, arte veterinaria, reloxería y ciencias naturales. Quan provecho sacaría el Reyno y la nación si se practicase esta diligencia." ${ }^{32}$
}

Desde Alcoi se dirige a Planes: «es intolerable el abuso de autoridad que se observa en este partido" advertirá al serle explicado el sistema de corta de matorral que se observaba en esta Baronía. Durante los días siguientes se ocupará de la morfología de los montes que rodean esta villa y de sus producciones minerales; los mármoles vuelven a cautivar su atención. Continúa por el Vall de Gallinera, dedicando su tiempo a la herborización; el día 11 de mayo amaneció con amenaza de lluvia, A.J. Cavanilles emprende viaje a Pego; allí le aguarda Pedro Pascual Sala:

«Empezó a llober con mucha fuerza continuando esta noche, todo el día 12 , y hasta las once de la mañana del 13 (...) En este tiempo procuré instruirme de quanto necesitaba, auxiliándome Salvador Mengual, labrador inteligente (...). Quando lo permitió el tiempo subí a algunas alturas y visité después aquellos sitios mas interesantes...» ${ }^{33}$

En compañía de Salvador Mengual se encamina a Orba, luego, atravesando Jalón y Lliber, alcanza Benissa, allí se hospedará en casa de José Felíu; el 16 de mayo emprende el estudio botánico del Peñón de Ifach. En el camino de vuelta a Benissa encuentra unas ruinas que habrían de llamarle la atención:

«Hablé de ellas al volver á casa con los Señores dn. Pedro Yvars, Presbítero, dn. Juan Antonio Feliu, Dn. Juan Bautista Feliu y Dn. Joseph Torres Ximeno (...) [ellos] me obligaron à destinar dos días para esta expedición, fol. 43).

32 A.J. CaVanilles, Diario de excursiones... [7-V-1792]. (A.R.J.B., leg: XIII,7,1, fol. 38).

33 A.J. Cavanilles, Diario de excursiones... [12/13-V-1792]. (A.R.J.B., leg: XIII,7,1, 
franqueándome el Sr. dn. Joseph Feliu su casa de campo (...) con obreros e instrumentos...» $)^{34}$

Estas excavaciones, en un terreno próximo a Calp, atrajeron vivamente a A.J. Cavanilles, hasta el extremo de considerarlas uno de los mayores logros de su viaje por Valencia; tras visitar otras ruinas, los Baños de la Reina, emprende camino hacia La Granadella, visita la cueva del Cap de Sant Martí, de la que hizo un breve apunte, y continuó viaje hacia Xàbia, allí:

\footnotetext{
«Hallé los dos mesones tan mal aviados que no encontré quarto alguno y me fue preciso pasar a casa de mi amigo y condiscípulo Dn. Jayme Cruañes.... ${ }^{35}$
}

Con él, y aunque poco propenso a realizar viajes por mar, se embarca para recorrer esta costa, en especial se interesa por las cuevas del litoral.

El 23 de mayo de este 1792 sale para Denia, por el camino de la montaña, bordeando la Serra del Montgó; en Denia visita a Carlos Vallés, cura de la ciudad y antiguo condiscípulo, prosigue camino hacia Gandía, atravesando el valle de Oliva, del que le admira el particular modo de regar los marjales. De Gandía le sorprende la población, siempre ocupada en los más diversos oficios, y los cultivos de moreras y caña dulce. Estudia, con cierto detenimiento, las huertas de los pueblos de su occidente (Ròtova, Marchuquera), le acompañan Carlos Siscar y Joaquín Maldonado, a todos les mueve el mismo interés por las producciones minerales y por la calidad de los suelos de estas tierras.

"Aquí si que podría asegurar el Sr. Bowles que la tierra es negra; pero decir que la tierra de la huerta de Gandía era de ese color es confesar que no la pisó o nunca reparó en su color verdadero.» ${ }^{36}$

La crítica al texto del viajero irlandés es continua; en la edición impresa de sus «Observaciones...» escribirá:

«Este autor dio solamente un bosquejo y nociones superficiales (...), excitando la curiosidad de sus lectores sin instruirlos á fondo en un objeto que le llenó de admiración: él tiró las primeras lineas del quadro; procuraré concluirle como pueda.... ${ }^{37}$

\footnotetext{
34 A.J. Cavanilles, Diario de excursiones... [16-V-1792]. (A.R.J.B., leg: XIII,7,1, fol. 47). fol. 51).

35 A.J. Cavanilles, Diario de excursiones... [21-V-1792]. (A.R.J.B., leg: XIII,7,1,

${ }^{36}$ A.J. CaVanilles, Diario de excursiones... [25-V-1792]. (A.R.J.B., leg: XIII,7,1, fol. $54 \mathrm{v}$ )

37 A.J. CAVANILles (1797), Observaciones sobre la Historia Natural, Geografía, Agricultura, Población y Frutos del Reyno de Valencia. Madrid (vol. 2, p. 141).
} 


\section{A. GONZALEZ BUENO}

Mas no nos salgamos del itinerario de esta expedición; desde Gandía prosigue viaje hacia Valldigna, herboriza el Mondúber y examina con atención el valle de Barx, de nuevo interesado en sus mármoles. Continúa por Llutxent y La Pobla del Duc, allí descansa, dibuja y confraterniza con su amigo Joaquín Ferrandis.

"Continue el camino hasta Valencia y me tomé algunos días ya para descansar de mis fatigas ya también para poner en orden mis dibujos, plantas y manuscritos, y en fin para dar cuenta al Excmo. Conde de Aranda de lo descubierto en 18 y 19 entre Calp é Hifac como lo executé con fecha de 5 de Junio de 1792. j $^{38}$

Escribió y lo hizo con la presteza acostumbrada; el 26 de junio de este mismo año, Guevara Vasconcelos notifica a Miguel de Otandi:

"Amigo mío: se corrigió la noticia de los descubrimientos que ha remitido Cavanilles; pero ha costado algún travajo, pues era día de Gazeta, y hasta las quatro y quarto de la tarde estuve sin comer en la Imprenta. En otra ocasión convendría tomar algún tiempo para evitar los inconvenientes, y descuidos que puede causar la precipitación con que se travajan estas cosas...n ${ }^{39}$

A la carta, hoy conservada en el Archivo Histórico Nacional, acompaña un manuscrito de A.J. Cavanilles: «Noticia del descubrimiento en la Marina de Valencia por el comisionado de S.M. $p^{a}$. el viaje científico de España...»

La tercera de las expediciones realizada por A.J. Cavanilles este año de 1792, la más extensa y de mayor duración, le aparta de Valencia el 13 de junio. Emplea este día en alcanzar Rotglá, atravesando L'Alcúdia y Alberic; asentado en este territorio, se interna en el valle de Càrcer, gira visita a las poblaciones del valle (Cotes, Càrcer, Alcántera de Xúquer y Beneixida), interesándose por la procedencia del agua que riega estas tierras, inspecciona la Azequia del Rey, y construye un mapa con la delimitación de las tierras del valle; describe la geología y flora de los monte de Sumacárcer y procura una diagnosis detallada de las acequias de Carcaixent y Castelló. Asciende por el cauce del Júcar hacia Millares, un camino áspero, falto de arbolado y de habitantes, poco grato:

\footnotetext{
38 A.J. Cavanilles, Diario de excursiones... [2-VI-1792]. (A.R.J.B., leg. XIII,7,1, p. $60 \mathrm{v})$.

39 Carta de Guevara Vasconcelos a Miguel de Otandi. Madrid, 26-VI-1792 (A.H.N., Estado, leg: 3022,7).
} 


\section{REFLEXIONES EN TORNO A LOS VIAJES DE A.J. CAVANILLES}

«Así continuamos sufriendo un calor fuerte y pisando el camino peor que se puede imaginar. ${ }^{40}$

Millares se anuncia con el olor «fuerte é insufrible» del esparto puesto a remojo para la fabricación de alpargatas; prosigue por un camino de

«desiertos y montes desmoronados (...) [que] obligan a pasar con recelo sino con miedo al que se ve precisado á entrar en Cortés (...) con todo tiene mucho atractivo para el que estudia la naturaleza. En parte alguna la he visto mas rica en vegetales... ${ }^{41}$

Descansa en Cortés de Pallás, y desde aquí decide bajar hacia Enguera; atraviesa Bicorp, interesándose por sus minas, los mecanismos de extracción del yeso y los defectos que observa en sus molinos de aceite; pasa por Quesa, un terreno que, recorrido ya el año anterior, apenas despierta su interés; sigue hacia Navarrés, describe sus fuentes, con cierta minuciosidad, y los lugares de Chella y Anna que salen a su paso, también se interesa por algunos ingenios construidos para aprovechar la fuerza producida por la caída de las aguas. Antes de examinar Enguera, se dirige hacia Montesa, describe su situación y las ruinas de su castillo; volviendo a su camino entra en Enguera, una villa industriosa, dedicada a la fabricación de paños y telas, para la que reclama la instauración de un montepío con el que «se acabaría de una vez con los traficantes del sudor del pobre»; inspecciona sus montes, ricos en vistas pintorescas.

Dedica el 25 de junio a ordenar sus manuscritos, luego retorna hacia La Muela de Bicorp; esa noche descansa en una "pobre choza». Al amanecer del día 26 prepara lo necesario para herborizar el Caroch; le acompañan los hijos de Fuster y Verger, propietarios de buena parte de aquellos montes. El Caroch no es de los picos más altos, pero en su opinión, "es el mejor balcón del Reyno»; de él, extrañamente, no hizo imprimir ninguno de los bocetos dibujados.

La expedición continúa hacia Cofrentes, allí le espera al viajero una extraña visita; se oculta en el pueblo un fugado de la justicia quien, temeroso de la presencia del visitante, envía a su mujer para cerciorarse de su identidad.

«Vio esta que ni mi carácter ni mi equipaje era de perseguidor de desertores y se fue contenta; dexándome à mi con deseos de salir de un pueblo

\footnotetext{
40 A.J. Cavanilles, Diario de excursiones... [16-VI-1792]. (A.R.J.B., leg: XIII,7,1, fol. 63v).

41 A.J. Cavanilles, Diario de excursiones... [16-VI-1792]. (A.R.J.B., leg: XIII,7,1, fol. $63 \mathrm{v})$
} 


\section{A. GONZALEZ BUENO}

poco seguro, en donde se oyen escopetazos y se sienten las valas sin que la justicia se altere ni se mueva. ${ }^{42}$

Abandona la villa de Cofrentes pero no su valle; visita Jalance y Jarafuel, donde se interesa por el sistema de cultivo de almeces y álamos; prosigue por Teresa y Zarra, ponderando sus cuidadas huertas, para concluir su viaje en Ayora; aquí se detiene para anotar la extensión de las tierras, el encadenamiento de los montes y, en particular, el del Meca, tan encomiado por Escolano,

«Mereció este monte una descripción pomposa de nuestros historiadores valencianos, y otros sin ser historiadores lo recomendaban por mil títulos; por lo qual y para separar lo verdadero de lo falso destiné los días 1 y 2 de Julio para examinarle. ${ }^{43}$

Tras la detenida descripción del monte, sus fuentes y sus vistas, pasa revista a los restos arqueológicos conservados, muy parcos para lo esperado; emprende desde aquí una visita al territorio limítrofe entre Murcia y Valencia, explora el monte Palomeras, interesándose por su composición mineral y realizando elementales pruebas de calcinación: estos materiales, como tantos otros, fueron numerados y remitidos a Madrid «donde se harán las experiencias»; luego habremos de enterarnos que, en Madrid, Domingo García Fernández realizaría pruebas analíticas sobre materiales acopiados por A.J. Cavanilles ${ }^{44}$. Desde Ayora, murcianos en otro tiempo y que "nada han adoptado de los del Reyno ó Valencianos», sale, en compañía de José Maldonado y los varones de la familia de José Ruiz, con dirección a Ibi; interesado durante todo el camino por el origen de las fuentes, descansa en Biar:

"Aquí comí en casa de mi amigo Santoncha, renové el conocímto. de los que me favorecieron en mi viage, y seguí por el puerto a la hoya de Castalla." 45

42 A.J. Cavanilles, Diario de excursiones... [27-VI-1792]. (A.R.J.B., leg: XIII,7,1, fol. 71v)

43 A.J. CavanIlles, Diario de excursiones... [1/2-VII-1792]. (A.R.J.B., leg: XIII,7,1, fol. 73).

${ }^{44}$ El mismo A.J. Cavanilles utiliza los resultados de los análisis realizados por D. GaRCfA FERNÁNDEZ (1797) en sus Observaciones sobre la Historia Natural, Geografía, Agricultura, Población y Frutos del Reyno de Valencia. Madrid (cf. vol. 2, pp. 110-114; 179).

45 A.J. Cavanilles, Diario de excursiones... [9-VII-1792]. (A.R.J.B., leg: XIII,7,1, fol. 79). 
El viaje, emprendido junto a Bartolomé Rico, sigue el canal de Alcoi; atraviesa Benifallim y Penáguila, interesado siempre en el origen de las aguas y en las producciones minerales del subsuelo. Acomete luego una visita al valle de Guadalest y sus montes, interesándose especialmente por el Aitana, "renombrado por la abundancia de fuentes y de plantas como también por competir con los mas elevados quando no sea el mas del Reyno...»; inicia su periplo el 12 de julio, con las plantas ya agostadas, lo que hace que sus impresiones se centren más en la calidad de las tierras y en la ubicación del valle; visita Callosa d'En Sarria: de nuevo las fuentes y las canteras de mármol retienen su atención; aquí se hospeda en casa de Andrés Ronda, continúa hacia Benissa, atravesando el collado de Bernia.

«En Benisa descansé un día para ver y tratar de nuevo los que me favorecieron en el viaje antecedente y supe que nadie a continuado los trabajos que empezamos entre Calp é Hifac. ${ }^{46}$

Amarga decepción que pronto habrá de verse compensada al recorrer las huertas de Altea; allí descubre un cultivo nuevo, el algodón, un sistema diferente para fertilizar los campos, valiéndose de Zoostera, y unas preciosas vistas, las del castillo de Altea.

«En Altea estuve en casa del Sr. Cura dn. Sebastián Aracil, quien no contento con suministrarme cuanto necesitaba para mi instrucción me acompaño hasta Benidorm y me facilitó el conocimiento de los Señores Dn. Manuel Fuster y dn. Manuel Orts. ${ }^{47}$

El término de Benidorm le parece "admirable progreso en población y agricultura»; le fastidia el sabor salobre del agua, y dedica algún espacio a describir la pesca del atún con almadrabas.

De Benidorm a Vila Joiosa sigue el camino de la playa; aquí se detiene a comentar la estructura del pantano y las mejoras que pueden introducirse en las condiciones del riego. Y de Vila Joiosa a Alacant:

«Gastaron mucho; trabajaron y trabajaron aun infinito los de Alicante, pero tienen la satisfacción de coger abundantes cosechas del mejor vino de España, de aceyte, algarrobas, seda, granos y frutas.» ${ }^{48}$ fol. $83 \mathrm{v}$ )

46 A.J. Cavanilles, Diario de excursiones... [15-VII-1792]. (A.R.J.B., leg: XIII,7,1,

47 A.J. Cavanilles, Diario de excursiones... [16-VII-1792]. (A.R.J.B., leg: XIII,7,1, fol. $84 \mathrm{v})$.

48 A.J. Cavanilles, Diario de excursiones... [20/22-VII-1792]. (A.R.J.B., leg: XIII,7,1, fol. 87).

Asclepio-Vol. XLVI-1-1995 
Las huertas de Alacant, a cuyo estudio dedica buen espacio en sus diarios, las recorre en compañía de Lorenzo Belón. De Alacant pasa a Santa Pola, donde «se experimentan algunas tercianas por el descuido que reyna en macerar el esparto (...) y coromper la atmosféra»; prosigue por Elx, cuyas tierras ya había visitado el año anterior, por lo que sólo se detiene para pasar la noche. Los saladares y las tierras pobladas por el cardenal Belluga atrajeron su atención en el viaje de 1791; en esta ocasión se dirige hacia los montes de Crevillente. Atraviesa Albatera, cuyo descuido en la agricultura atribuye a «la inaccion del dueño territorial», el Marqués de Dos Aguas; continúa hacia Callosa de Segura, examina la sierra homónima a la población y prosigue camino hacia Orihuela; llega al término el 25 de julio y al siguiente día, en compañía de Joaquín Barrera, se dirige a casa del «famoso Estevan de quien nos contó embuestes el gazetero; y las salinas que no pude visitar el año pasado». El tal Esteban, Esteban Casteló e Yborra, es un caso de masoquismo que ha derivado en demencia con visos de asceta, y las salinas son las de Torrevieja. A éstas dedica una detenida descripción en sus diarios: su situación, extensión y calidad del suelo, el modo de cristalización, los posibles perjuicios para la salud, el sistema de extracción y algunas ideas para mejorar su rendimiento, ocupan varias páginas en la apretada letra de A.J. Cavanilles.

Prosigue viaje hacia Guardamar del Segura, parajes de tierras cultivadas, aunque con descuido, donde el regaliz crece como mala hierba:

«En Francia, en donde todo se mete á contribucción para aumentar la masa de riquezas y comercio hacen uso de la regalicia (...) se distribuye en pastillas ó en granitos como confites (...) Si nuestros boticarios supiesen esto y mayormente si se asociase la virtud de la regalicia y se practicase en España, aun podrían sacar partido á las rayces.. ${ }^{49}$

De vuelta, atraviesa Rojales, las inmediaciones de Almoradí, y alcanza Benejúzar; un recorrido que debió ser muy similar al realizado el año anterior, y con el que obtiene suficientes datos para dar una visión general sobre las huertas de Orihuela, sus problemas y las posibles soluciones; aplaude los intentos de aclimatación de los naranjos chinos, aunque pone en tela de juicio la elección de los pies, recomendando el uso de injertos; alaba las nuevas fundaciones, mostrándose partidario de fomentar la práctica poblacional con el deseo de ampliar el cultivo en terrenos hasta entonces estériles.

Acabado el examen de las huertas, pasa a estudiar la naturaleza de los montes; recorre la Sierra de Orihuela, se detiene en describir su composición

49 A.J. Cavanilles, Diario de excursiones... [26/27-VII-1792]. (A.R.J.B., leg: XIII,7,1, fol. 93). 


\title{
REFLEXIONES EN TORNO A LOS VIAJES DE A.J. CAVANILLES
}

geológica y en glosar el paisaje: «La vista que se descubre es de las mas graciosas del Reyno.» Destina los últimos días de julio "a poner algún orden en los apuntamientos, piedras y dibuxos», se despide de sus amigos "y principalmente del que me hospedó dn. Bruno Andreu » y, al día siguiente, sale para Crevillente. Allí, acompañado de Paulino Cortés, el cura párroco, recorre las fuentes, minas y tierras del término; alaba la industriosidad de sus gentes, volcada en las fábricas de esteras de juncos, pleitas de esparto y en trabajos de arriería; el cuidado de las huertas le entusiasma, pero sobre todo llama su atención sus esfuerzos por obtener y canalizar las aguas, la construcción de minas subterráneas para este fin le encandila:

\begin{abstract}
"Quando nuestros sobrinos lleguen á ver siquiera algunos rastros de esta obra, dirán con justicia lo que nosotros al ver los monumentos de Roma en las $\operatorname{artes...{}^{50}}$
\end{abstract}

El día 2 de agosto llega a Elx, aprovecha el tiempo en preparar sus plantas y ordenar sus apuntes; al día siguiente pasa a visitar su pantano, apenas hay descripción de este terreno, ya comentado en un viaje anterior, cuyo diario no conservamos. De Elx se dirige a Alacant «por el mismo camino que traxe el año pasado», con la única intención de describir el Raspeig. El 4 de agosto vuelve a Alacant para pasar la noche e iniciar camino hacia Monforte y Novelda. Tras examinar estas tierras se dirige hacia Agost, interesándose por el sistema de encañonado para el desagüe de las huertas; sigue hacia Aspe, desde donde manifiesta sus críticas contra el abuso de tala cometido en el término, y sobre todo admira los mármoles de la iglesia local, sus canteras son descritas en el diario con prolija minuciosidad, acaso porque no estuvieran contempladas en sus escritos del año anterior, donde debió ocuparse ya de las aguas y producciones de estas tierras.

Continúa el viaje por Monóvar, se asombra ante el cerro del Pinazo, de sal virgen, al que apenas dedica comentario; sigue a Elda, herborizada ya en 1791, y de la que ahora ofrece un estudio de sus fuentes; su visión sobre la industria del esparto le apartan de la tesis defendida por el Conde de Cabarrús, recientemente confinado por Floridablanca en el castillo de Batres; A.J. Cavanilles no duda en atacar al depuesto director del Banco de San Carlos, calificando sus intentos de reorganizar los caminos entre las tierras de Aguilas y Elda como «operación antinacional» ${ }^{51}$; obviamente estos comentarios no aparecerían en la edición

\footnotetext{
50 A.J. Cavanilles, Diario de excursiones... [31-VII-1792]. (A.R.J.B., leg: XIII,7,1, fol. $95 \mathrm{v})$.

51 A.J. Cavanilles, Diario de excursiones... [11-VII-1792]. (A.R.J.B., leg: XIII,7,1, fol. 104).
} 
publicada de sus «Observaciones....»: tras la rehabilitación política de Francisco Cabarrús hubieran sido imperdonables para la carrera de A.J. Cavanilles.

Desde Elda se dirige a Petrer, sigue por Sax, a cuyos habitantes dirige un sonoro elogio, en letra de A.J. Cavanilles ( $" L o s$ de Sax aunque Murcianos cultivan sus tierras como los Valencianos») para pasar la noche del doce de agosto en Villena, donde da por terminado éste, su tercer periplo del verano de 1792, no sin antes dejarnos una síntesis del viaje, en unas instrucciones sobre el modo de recuperar los recursos de leña de los montes de Valencia, ciertamente interesantes, además de un parco comentario biográfico: «33 años que no havía yo visto las inmediaciones de este lugar á donde varios niños solíamos concurrir para correr y divertirnos ${ }^{52}$.

El 22 de agosto inicia A.J. Cavanilles la cuarta expedición de las efectuadas en 1792; sus intereses vuelven a decantarse por las producciones de mármoles. Tan entrado el verano parece insensato plantearse una campaña de herborización, pero sí podrán fijarse lugares a los que volver en años posteriores. Inicia su periplo en Moncada para alcanzar pronto las tierras de Nàquera, famosa por sus canteras de mármoles, a las que dedica especial atención; sigue camino hacia Serra, de nuevo interesado en sus huertas, fuentes y minerales. Esta vez atrae su interés una mina de plomo; en su búsqueda de vetas marmóreas se dirige hacia el convento de Porta-Coeli, le atrae su magnífica iglesia, rica en mármoles, de la que nos ofrece una detallada descripción del pavimento y paredes, pero ni una sola letra acerca de la iconografía o la liturgia del Centro; no hay duda de que el viajero se interesa más por las producciones naturales que por la vida religiosa.

\footnotetext{
«En general todo es magnifico en esta Cartuxa y anuncia que tienen poder y gusto sus dueños, los cuales se reserban para si la mortificación en todo genero, y se distinguen en cortexar á quantos allí llegan.. ${ }^{53}$
}

Tras dormir en la cartuja emprende camino hacia Olocau, para proseguir luego hacia Llíria y, por Pedralba y Bugarra, alcanzará las tierras de la Baronía de Chulilla. Un recorrido con el que pretende formarse una idea global de las huertas regadas por las aguas del Turia. Una inesperada lluvia de verano le retiene en Chulilla durante dos días; en cuanto las condiciones climáticas se lo permiten, inicia el estudio de los montes de la zona, con el objeto de fijar los límites de las propiedades en el territorio que ha recorrido, a la vez que preparar la continuación de su viaje.

52 A.J. Cavanilles, Diario de excursiones... [13-VII-1792]. (A.R.J.B., leg: XIII,7,1, fol. 106v)

53 A.J. Cavanilles, Diario de excursiones... [25-VIII-1792]. (A.R.J.B., leg: XIII,7,1, fol. 110). 


\section{REFLEXIONES EN TORNO A LOS VIAJES DE A.J. CAVANILLES}

Se encamina hacia Chelva. Antes atravesará Domeño, rico en yesares, y Calles, «lugar mal sano y expuesto a tercianas por la corrupción de las plantas y (...) aguas»; Chelva es villa industriosa, rica en huertas, admira "el genio amable de sus moradores" y anota su enfermiza pasión por el picante; no se olvida de su acueducto romano, del que nos legó una extensa descripción y su dibujo.

En las proximidades de Chelva, camino a Tuéjar, encuentra un pequeño terreno utilizado como eremitorio; el hecho nos permite disponer de una revelación personal sobre su carácter:

«No hay duda de que el sitio es sumamente solitario y fragoso mas propio para habitación de fieras que de racionales; pero hay hombres que se condenan voluntaria ${ }^{\mathrm{mte}}$. a esta pena que para mi seria insoportable. ${ }^{54}$

Un duro comentario para quien, a los pocos años, recibiría el nombramiento de prior de las ermitas de Sevilla ${ }^{55}$, ciertamente honorífico, como siempre habíamos supuesto; mas sigamos con nuestra reconstrucción del viaje.

El camino de Chelva a Tuéjar lo realiza en compañía de Salvador Sagarriga, "cuyos padres me honraron sobremanera en Chelva». Sus observaciones versan ahora sobre el vestido y el lenguaje de las gentes, un tema apenas abordado en los diarios de este año; desde Tuéjar, «sufriendo un sol ardiente», se dirigen a Titaguas, el camino es difícil, el sol agotador y, para colmo, los mesones de estos pueblos «se reducen a simple cubierto sin cuartos ni camas, de modo que es preciso recurrir al favor del cura o de otra persona para alojarse». Su atención queda centrada en los recursos minerales del terreno; pocos datos puede obtener de la vegetación, toda agostada; la excursión continúa por el Rincón de Ademuz. Además de fijar bien sus límites, corrigiendo "el mapa de López", se ocupa de los aspectos ya tradicionales: las fuentes, el curso de los ríos, la calidad de los suelos, la vegetación y las producciones agrícolas de los pueblos que componen esta comarca; de ella nos dejó un mapa, impreso en sus "Observaciones...".

Prosigue su viaje por Alpuente, La Yesa, Andilla y Alcubla, visita La Cueva Santa; siempre ocupándose del origen de las aguas de riego y de las producciones agrícolas, y corrigiendo el mapa de T. López de Vargas, cuyos «hierros» son señalados de manera profusa, hasta el extremo de parecer un tema obsesivo: al pasar por Andilla admira las pinturas de Ribalta conservadas en

54 A.J. CaVanilles, Diario de excursiones... [31-VIII-1792]. (A.R.J.B., leg: XIII,7,1, fol. 115).

55 De ella tomó posesión en 1802 (datos sobre esta dignidad en A.R.J.B., legs: XIII,1,26,1 / XIII,1,26,9). 
su iglesia parroquial, una de las pocas alusiones a este arte que hemos encontrado en sus diarios.

Desde el santuario de La Cueva Santa se dirige hacia Segorbe, analiza los cultivos de olivo, que encuentra defectuosos, y discute la posibilidad de plantar algarrobos, con apreciaciones que encajarían hoy, conceptualmente, en el ámbito de la ecología. Dispuesto a conocer los términos que riega el río Palancia, baja hasta Petrés, para ascender el cauce del río por Albalat y Estivella, se detiene en los parajes de la Baronía de Torres-Torres; continúa el examen del río hacia el origen, esto es, por los términos de Algar, Sot y Soneja, para retornar a Segorbe. Siguiendo en las riberas del Palancia, prosigue su viaje por tierras de Altura y Navajas, donde deja anotado que ha de volver por mayo para herborizar, se acerca luego a los bancos marmóreos de Jérica y Caudiel, para alcanzar, por último, La Peña Escabia, un volcán apagado, donde sitúa el nacimiento del Palancia. Esta excursión, en la que ha ocupado la segunda semana de septiembre, le sirve para pronunciarse sobre el modo en que deben ser cultivados los ribazos, mediante un sistema de emparrados, similar al empleado en Xixona y Chelva. Sin apartarse de las márgenes del Palancia, recorre Viver, Bejís y Teresa, dirigiéndose a los pueblos de la raya de Aragón; visita Pina, Villanueva de Viver (a la que denomina Villanueva de la Reyna) y Montán, se detiene en las aguas termales de Montanejos, cuyo análisis no puede realizar "por faltarme los instrumentos», y continúa por el curso del río Millares. Viaja acompañado de Juan Bautista Noguera, quien le informa sobre las producciones y caminos de éstos y otros pueblos de la Baronía de Ayodar, en las proximidades de la Serra d'Espadà. Siguiendo el curso del Millares, alcanza Fanzara y Ribesalbes, ambos en la margen izquierda, tierras de arcillas y alfares, desde donde continúa a Onda: allí le espera Francisco de Miralles, cura párroco de la villa, con quien visita la ermita y el castillo, interesándose por las canteras de mármol y su explotación. Desde Onda vuelve a internarse en la Serra d'Espadà, para recorrer, de nuevo, tierras de la Baronía de Ayodar, unas tierras a las que la tradición considera muy ricas en metales, afirmación que A.J. Cavanilles desmiente en el curso de sus «Observaciones...».

Vuelve sobre sus pasos para retornar a Ribesalbes, donde le espera José Faustino Alcedo, canónigo de Valencia, con quien le une cierta amistad; prosigue por Villafamés, para atravesar el Desert de les Palmes, un terreno ya conocido de excursiones anteriores pero que le permite acercarse al arco romano de Cabanes, cuya descripción y dibujo se conservan; prosigue por las tierras del Señorío de l'Alcalatén, con ánimo de completar el viaje del pasado año, describe en éste Costur y Alcora, visita la fábrica de porcelana del Conde de Aranda, para quien no omite elogios, y retorna a su camino para internarse en la Serra d'En Galcerán, ya herborizada en un viaje anterior y de la que ahora hace algunas anotaciones geográficas; visita las Cuevas de Vinromá 
(sub Cuevas d'Aben Romá) y Salsadella, para alcanzar Sant Mateu; no son de su agrado las gentes que habitan estos valles: «En una palabra hay poca aplicación y degeneran del genio laborioso del valenciano» ${ }^{56}$.

Desde aquí alcanzará Cervera del Maestre, interesándose por sus canteras de mármoles y explicando la poca población de estos términos por la parca disponibilidad de aguas, algo que llegará a generalizar para todo el septentrión valenciano y que, en su opinión, será la causa de la pobreza de estas tierras. De Cervera, siempre interesado por la vegetación de los margales, baja hacia la hoya de Alcalá de Chivert, visita Vilanova d'Alcolea y continúa, por las canteras de Cabanes, hasta Villafamés, por un territorio ya recorrido durante el año anterior y del que apenas escribe sus impresiones.

La última anotación en su diario de viaje del año 1792 lleva fecha de 3 de octubre; se corresponde con el final de la cuarta excursión realizada ese año, cuyo itinerario acabamos de reconstruir, y acaba con un canto al trabajo del pueblo valenciano:

«Nada desprecia el valenciano; si halla obstáculos los vence con tesón; si el suelo es ingrato lo mejora; si es feraz exige de el continuas cosechas; y así dominado el suelo que le cupo, varía las producciones corrige el estado, y vive alegre y feliz en la abundancia que criaron sus manos, su industria, su constancia, su talento.... ${ }^{57}$

Los siguientes datos de que disponemos corresponden al 16 de abril de 1793. A.J. Cavanilles se encuentra en Silla, y dedica estos días a recorrer las tierras próximas a l'Albufera y el cauce del Xúcar, visitará Sueca y Cullera, para continuar por Algemesí y Guardamar; se interesa esta vez por las tierras regadas con la Real Acequia de Alcira y, en particular, por un conducto subterráneo, el caño de Algemesí. Es todo un cultivar de arroz, y sus críticas hacia este cultivo son bien conocidas;

«Si es laudable y aun justo el que se destinen dichas tierras [las de l'Albufera] a este cultivo; es reprehendible e injusto el abuso que se hace en la ribera alta, en donde se convierten en arroz los excelentes campos de huerta...» ${ }^{58}$

No perderá ocasión de manifestarse contra esta «pasión del arroz» que se ha apoderado de los habitantes de las cercanías de Valencia; continúa su via-

56 A.J. Cavanilles, Diario de excursiones... [28-IX-1792]. (A.R.J.B., leg: XIII,7,1, fol. 136).

57 A.J. Cavanilles, Diario de excursiones... [3-X-1792]. (A.R.J.B., leg: XIII,7,1, fol. 141v).

58 A.J. Cavanilles, Diario de excursiones... [16-IV-1793]. (A.R.J.B., leg: XIII,7,2, p. 4) 
je por Alzira, en compañía de Francisco Andrés, y aún obsesionado por los arrozales y su influencia en la salud; llegará al Monasterio de la Murta, y aquí su pasión de florista vence a la del fisiócrata que lleva dentro, conversa con fray Andrés Martí, cirujano del Monasterio, e incluso anota las propiedades medicinales del símfito, algo poco frecuente en la obra de A.J. Cavanilles: el interesarse por el empleo medicinal de las plantas. Desde la Murta, atravesando Llaurí y Riola, retorna a L'Albufera, hacia Sueca; los marjales de estas zonas sí le parecen terrenos adecuados para el cultivo de arroz:

«Así pues lejos de prohibir el cultivo de arroz en los sitios donde hoy se practica, debía concederse libertad absoluta para reducir a dichos cultivos los marjales que existen incultos y anegados.» 59

Así lo practican en Tavernes, hacia donde ahora se dirige:

\footnotetext{
«... determinaron introducir el cultivo del arroz, haciendo con una acción sola dos grandes beneficios que fueron mejorar la condición de la atmosfera y aumentar la masa de las riquezas nacionales. ${ }^{60}$
}

Ya en Tavernes, atravesará el valle de Valldigna, deteniéndose en el monasterio inmediato a Simat; todo son elogios para el cuidado con que los monjes trabajan la tierra,

"si hay algo que reprehender en su conducta en el exceso de beneficiencia, es la costumbre antigua de dar al medio día y a la noche la sopa y pan a quantos llegan; porque esta seguridad hace indolentes a muchos de sus vecinos.... ${ }^{61}$

Desde Valldigna se encamina hacia el valle de Aguas Vivas, visita Carcaixent, admirando sus soberbias moreras y los cultivares de naranjos chinos y granados, a la vez que se ratifica en la conveniencia de destinar los marjales de los ríos al cultivo del arroz, pero no otras zonas que bien pudieran dedicarse a huertas; alcanza Manuel, un «lugar malsano» por el cultivo extensivo de arrozales; la sal de sus salinas sí le parece explotable; pasa luego a San Felipe, "con animo de examinar la mina de carbón de piedra que tanto me celebraron el año pasado", sigue por Canals, donde se interesa por el uso de la pita, sus fábricas de cerámica y por la construcción del nuevo acueducto;

\footnotetext{
59 A.J. Cavanilles, Diario de excursiones... [19/20-IV-1793]. (A.R.J.B., leg: XIII,7,2, p. 10).

${ }^{60}$ A.J. Cavanilles, Diario de excursiones... [21-IV-1793]. (A.R.J.B., leg: XIII,7,2, p. 12).

${ }^{61}$ A.J. CaVAnIlles, Diario de excursiones... [22-IV-1793]. (A.R.J.B., leg: XIII,7,2, p. 13).
} 


\section{REFLEXIONES EN TORNO A LOS VIAJES DE A.J. CAVANILLES}

vuelta a San Felipe el día 27 de abril para ocuparse de las tierras dedicadas al arroz; no admite su cultivo en Genovés, tampoco en el Lugar Nuevo de Fenollet, ambos con tierras aptas para otros cultivos; su opinión es determinante:

«... la razón, la humanidad y la justicia debían pronunciar el decreto irrevocable de proscripción [de este cultivo] en donde la experiencia enseña que disminuye y aun perece nuestra especie.» ${ }^{62}$

Prosigue su recorrido por Villanueva de Castellón ( $s u b$ Castelló de Xátiva), sitiada por los arrozales, sigue hacia el norte, hasta Alberic, donde el paisaje ya verdea con las moreras, para salir al Camino Real; por él llega a Masalabés, siempre preocupado por los problemas de salud que plantean los arrozales. Deseoso de salir de estas «tierras del arroz» se dirige hacia L'Alcudia, en dirección al Condado de Carlet: aquí vuelve a manifestar su interés por el agua de riego, llegando a proponer algunas medidas para aumentar su rendimiento; a la sazón se habían manifestado en el pueblo algunos casos de viruela que el médico local no supo controlar: "Que lastima que el medico de la villa viva aun preocupado contra la inoculación!» 63

Desde Carlet se dirige al Marquesado de Llombay, describe el territorio desde el campanario de Alfarp, y relata las producciones del término de Alginet; cruza el Camino Real para dirigirse a Benifaió, y desde allí, de nuevo, hacia los arrozales de L'Albufera, atravesando Sollana y Silla, ya de vuelta a la ciudad de Valencia.

Debió permanecer en Valencia entre el 2 y el 5 de mayo; al amanecer del 6 sale por la Puerta del Real con destino a Manises; es la segunda expedición de este año, muy breve, de tan sólo nueve días. Manises es tierra reconquistada para la huerta: en ella se prohibió el cultivo y, desde entonces, de creer a A.J. Cavanilles, «se vio renacer la felicidad». Anota sus impresiones sobre las fábricas de loza y continúa viaje a Paterna, allí describe, a más de sus huertas, las fábricas de cordel de esparto; come en Bétera, y pasa al Monasterio de Porta-Coeli para cumplir uno de los objetivos de este viaje, herborizar estos montes y contrastar sus observaciones florísticas con las de su viaje del año anterior. De Porta-Coeli se dirige a Benaguasil y Vilamarxant, analizando el curso de las acequias en estos terrenos, la mayoría incultos pese a la disponibilidad de aguas; con estas visitas, y una última al término de Riba-roja de Turia, da por concluido el examen de los pueblos en que, hasta 1769, se cultivaron arrozales; éste es el eje central de esta segunda excursión de 1793,

\footnotetext{
62 A.J. Cavanilles, Diario de excursiones... [27-IV-1793]. (A.R.J.B., leg: XIII,7,2, p. 22).

${ }^{63}$ A.J. Cavanilles, Diario de excursiones... [29-IV-1793]. (A.R.J.B., leg: XIII,7,2, p. 27).
} 


\title{
A. GONZALEZ BUENO
}

complementaria a la realizada durante las semanas anteriores a los pueblos donde aún se practica este cultivo. $\mathrm{El}$ asunto requiere una recapitulación que queda explicitada en sus diarios:

\begin{abstract}
«... son menos peligrosos las habitaciones de Silla, Sollan, Sueca y Cullera, que las de Alcira, Guardamar, Castelló, Señera, lugares de Cueva y valle de Carcer. [En las primeras] no se padecen tercianas rebeldes; lo que se debe atribuir á que los vientos reynan con bastante fuerza del levante y barren sin cesar los vapores, renovando la atmosfera. [Las últimas] reciben los vapores que los vientos trahen de levante, añadiéndose a ellos los muchos que se levantan de los arroces de sus términos. Esta masa de infección halla dificultad en circular por tropezar en cerros y montes. De modo que el cultivo del arroz es sumamente perjudicial en estos últimos lugares, como queda dicho.» ${ }^{64}$
\end{abstract}

Desde Riba-roja pasa a Cheste, dedicado a la doble industria de la arriería y el esparto, continúa por Chiva, de amplio término para una baja población $\mathrm{y}$, tras una pequeña incursión por las tierras y canteras de mármol del Condado de Buñol (Yátova, Macastre y Alborache), se dirige hacia el oriente, hasta alcanzar Turís; de esta villa le sorprende su iglesia «espaciosa y como tapizada de mármoles", procedentes de las canteras locales que, por supuesto, pasa a visitar. Continúa su camino por el espacio creado entre la Serra Perentxissa y el Marquesado de Llombay, para llegar a las tierras del Marquesado de Dos Aguas, en Picassent y, desde aquí, hacer su entrada en la ciudad de Valencia.

El 22 de mayo emprende su tercera excursión de este 1793. Sale por el Puig, atraviesa las huertas de Puçol y alcanza el Morvedre, un camino que ya ha sido explorado en viajes anteriores y al que apenas dedica atención; sí se detiene algo más en sus comentarios sobre Canet y Almenara, para anotar los fallidos intentos de aclimatar en estas tierras el arroz; continúa por La Llosa y Chilches, para entrar en el Marquesado de Nules, lugares ya descritos en viajes anteriores y a los que apenas presta atención en éste, salvo en lo que afecta a los daños producidos por el arroz, una obsesión que arranca de las primeras expediciones realizadas este año y que ha pasado a convertirse, prácticamente, en el monotema de sus diarios. Continúa viaje por Mascarell, Burriana y Almanssora, atraviesa el puente construido por Ribelles (al que dedica cierta atención) y, siguiendo el Camino Real, se dirige a Castelló de la Plana; es todo un territorio ya conocido por viajes anteriores: ahora perfila sus observaciones, añade algunos detalles y, sobre todo, aporta una informa-

${ }^{64}$ A.J. CaVanilles, Diario de excursiones... [9-V-1793]. (A.R.J.B., leg: XIII,7,2, p. 38). 


\section{REFLEXIONES EN TORNO A LOS VIAJES DE A.J. CAVANILLES}

ción exhaustiva sobre las zonas destinadas a arrozales y ofrece datos demográficos sobre las poblaciones próximas a éstos.

Continúa su viaje por Benicàssim, donde visita el jardín de Francisco Pérez Bayer: allí describe un pie de aloe; prosigue por Orpesa, haciendo observaciones sobre la dirección de los vientos que soplan del mar y su influencia sobre el problema epidémico; vuelve a Benicàssim y, desde aquí, se dirige al Desert de les Palmes: ya había escrito sobre él con ocasión del viaje efectuado durante el año anterior, pero deseaba verlo en primavera; allí herboriza durante los últimos días de mayo. De aquí pasa a Villafamés, continúa por Les Useres, Figueroles y Lucena, dejando consignados los datos sobre sus herborizaciones en estos lugares. No menudean las plantas nuevas que verán la luz publicadas en sus "Icones...» ${ }^{65}$, pero pocas apreciaciones más en un terreno ya descrito en las páginas anteriores de sus diarios.

Prosigue este itinerario por Ludiente, Zucayna, Cortes de Arenoso y Villahermosa del Río, preparando el ánimo, y el cuerpo, para la ascensión a Penyagolosa; la botánica sigue copando su atención, herboriza en compañía de Juan Antonio Barrera, boticario de Vistabella del Maestrazgo, "que es ciertamente el mas instruido en Botánica de todo el Reyno»; estas recolecciones convertirán a Penyagolosa en el loco classico valenciano por excelencia ${ }^{66}$.

Continúa viaje por Villafranca del Cid y Ares del Maestre, en una perpetua queja sobre la dificultad para pernoctar que encuentra en todo el Alt Maestrat; son tierras de pastos y ganados, poco gratas para el gusto de A.J. Cavanilles, quien sólo encuentra gratificaciones en su afición botánica; pasa a Castellfort, descuidado en las labores de cultivo, piensa continuar hacia Cinctorres pero, siguiendo las indicaciones del cura de la villa, se desvía hacia Portell de Morella para examinar unas minas de hierro y desencamina lo andado para acercarse a Cinctorres, en particular hacia el monte de Bobalar, tan prolijo en ejemplares para su herbario.

El día 13 de junio, el de su onomástica, dice misa en Cinctorres, muy de mañana, para dirigirse hacia Forcall: aquí se interesa por los ríos y canales que confluyen en el término muy próximo a los límites del antiguo reino; desde Forcall se encamina a La Mata de Morella, por un camino «tan igual y tan ancho (...) que a poca costa podrían rodar coches»; es éste de La Mata uno de esos términos que A.J. Cavanilles califica de «infeliz» por la poca riqueza que les proporciona la agricultura; peores calificativos aplica a Todolella: él dedi-

\footnotetext{
${ }^{65}$ Un listado de las plantas descritas por A.J. Cavanilles en J. Fernández CaSAS y R. GARILlETI Alvarez (1989), «Nomina plantarum in bibliographia cavanillesiana provenientia». Fontqueria, 26: 1-176. Madrid.

66 Así lo calificó S. Rivas GodaY (1946), "Dos plantas cavanillesianas». Anales del Jardín Botánico de Madrid, 6: 397-414. Madrid. Ib. (1974), "Cavanilles, precursor en la Geografía Botánica». Anales de la Real Academia de Farmacia, 40(3-4): 403-419. Madrid.
} 


\section{A. GONZALEZ BUENO}

ca su tiempo a herborizar en estas tierras abandonadas por sus propietarios y aún por los encargados de la cura de almas:

«He visto por estas tierras una injusticia autorizada por la costumbre y es que cobra la primicia quien no alimenta espiritualmente al pueblo» ${ }^{67}$.

Un comentario algo difícil de compaginar con su propia situación; mientras recorre el viejo Reino de Valencia, él mismo está cobrando los diezmos de la mitra de Córdoba $^{68}$, una tierra que, como él confiesa, jamás había pisado.

Con centro en Forcall, herboriza por las márgenes del río Bergantes hasta alcanzar Morella; desde aquí visita Castell de Cabres: el paisaje es ahora un bosque de pinares que, camino a El Boixar, se transformará en un paisaje dominado por el boj. Abandona el terreno montano en su viaje hacia la Puebla de Benifasar, continuará por El Bellestar hasta alcanzar el Convent de Benifassà, «en otras partes son perjudiciales al estado [las] limosnas por contribuir a la holgazanería, pero aquí son necesarias para que se conserve la población ${ }^{69}$; en este monasterio bernardo conoce a dom Mauro Sospedrá, un monje «no menos curioso que instruido" con quien recorrerá las Muntanyes de Benifassá, estudiará los manuscritos del Monasterio en busca de datos sobre la explotación de estas tierras, y recorrerá los montes al acecho de minas de carbón fósil; de él se despedirá cuando emprenda camino a Rossell.

La pobreza de las tierras de Morella le conmueven, cree que parte del problema se podría solucionar si el control sobre los montes no fuera tan caciquil; la actitud del comisario regio, encargado de proteger la producción de estos montes para el uso de la Real Armada, le parece digna de reproche, y no ahorra críticas a su labor.

Los términos de Rossell, Vallibona y Vallivana, por donde continúa su viaje, le producen la misma impresión que las tierras de Morella: «todo es pobreza» escribe en cada página; algo mejoran las condiciones para los habitantes de Catí y Chert, ubicados en suelos "mas templados»; Canet lo Roig le parece lugar más habitable, «a excepción del naranjo todo se cría en el termino de Canet»; ya con un paisaje más de su agrado, recorre La Jana, Traiguera, Cervera y Càlig, continúa por Vinaròs, allí descansa en casa del cura, donde tam-

\footnotetext{
${ }^{67}$ A.J. Cavanilles, Diario de excursiones... [15-VI-1793]. (A.R.J.B., leg: XIII,7,2, p. 80).

${ }^{68}$ La concesión de su pensión sobre los frutos y rentas de la mitra de Córdoba data de 1789; sobre ella, y los rendimientos producidos, se conserva abundante documentación en A.R.J.B., legs: XIII, 1,26,10 / XIII,1,26,29.

69 A.J. Cavanilles, Diario de excursiones... [20-VI-1793]. (A.R.J.B., leg: XIII,7,2, p. 86).
} 
bién se hospedaba el de Cervera: los tres en unión pasan a las tierras de Benicarló con destino a Peñíscola; nuestro viajero prosigue el camino hacia Alcalá de Chivert, cuyos mármoles ocuparon ya su atención años atrás, allí reside en casa de su amigo Jaime Rodrigo, con quien visita las Cuevas de Vinromá, pasa luego a Pobla Tornesa, con el único interés declarado de ver a sus amigos. Al día siguiente continuará viaje hacia el sur, hacia Borriol y Onda, para adentrarse en la Plana Baixa en dirección a La Vall d'Uixó, atravesando Villavieja y Nules, en un camino ya recorrido en el viaje de 1791.

El 13 de julio da por concluida ésta, su tercera expedición de 1793. A los tres días, el 16 de julio, escribirá, desde Valencia, al Duque de la Alcudia:

«Desde que tuve el honor de tomar las ordenes de V.E. he examinado con cuidado los pueblos de este reyno en donde se cultivan los arroces, y he visto que el cultivo de esta planta es útil (...) [en las] inmediaciones al lago, pero sumamente perjudicial a la salud en los otros. En muchos de estos se prohibió ya por Real Orden y desde entonces renació la salud y la felicidad.

He recorrido también mas de cincuenta pueblos de los montes que confinan con Aragón y Cataluña, y vi que esta porción del reyno es sumamente pobre por verse reducida casi únicamente á granos; pero mas aun por no serles permitido cultivar mas terreno porque lo prohibe el Comisario de Morella. Si la piedad del Rey les permitiese romper y cultivar los eriales en donde ni nacieron ni prosperan las encinas y pinos seria menor la miseria de esta gente laboriosa. Desean emplear sus brazos pero hayan a cada paso celadores y multas que les arruynan. He visto extensiones inmensas sin un árbol, pobladas solamente de humildes coscoxas, en donde no pueden entrar ni á cortar leña para beneficiar los campos, ni menos reducir á cultivo sin repetidas visitas y licencias... ${ }^{70}$

La exposición de A.J. Cavanilles pudo parecer demasiado larga al Príncipe de la Paz, que debió contentarse con leer sólo el primer párrafo del informe; al margen de la carta anotó:

«... hace tiempo solicitan lo de los Arroces, y no me parece lo consigan, pasese no obstante á hacienda aunq ${ }^{\mathrm{e}}$. creo de la consulta se able en el Consejo para $\mathrm{q}^{\mathrm{e}}$. aga lo $\mathrm{q}^{\mathrm{e}}$. paresca."

El día 5 de agosto, A.J. Cavanilles inicia la que habría de ser su última expedición por las tierras de Valencia; atraviesa el Xúcar, alarmado por el incremento de las tierras dedicadas a arrozales en las proximidades de Manuel; se dirige a Benigànim y prefiere hacerlo por Genovés, sigue hacia el

70 Carta de A.J. Cavanilles al Duque de la Alcudia. Valencia, 16-VII-1793 (A.H.N., Estado, leg: 3022,7).

Asclepio-Vol. XLVII-1-1995 


\section{A. GONZALEZ BUENO}

oriente, hacia los terrenos de la Baronía de Llutxent, todos ellos dependientes en su economía de las fábricas de paños de Alcoy; sube al puerto de Salem, en un día sin nubes ni nieblas: "no hay en todo el Reyno de Valencia mejor punto de vista, ni sitio mas estéril...»; cruzará el río Serpis para alcanzar Gorga; la economía de estos pequeños valles que atraviesa A.J. Cavanilles es toda dependiente de las fábricas de Alcoi, por lo que las descripciones geográficas, ausentes las recomendaciones sobre cultivos, se reducen a la mera ubicación de los lugares y a algunas consideraciones sobre sus producciones; no son pueblos del agrado del viajero,

«No hay que esperar hallar en este valle mesones ni provisiones. Ni hay carnicería ni abastos. Pobre del que viaja si no trae consigo lo necesario.» ${ }^{71}$

Más le complacen las tierras de la hoya de Castalla, a la que dirige sus pasos; visita Ibi, Xixona y Tibi, donde vuelve a encontrase con sus amigos, para los que dedica, en su diario, palabras de agradecimiento; volverá sobre sus pasos hacia Ibi para alcanzar, desde aquí, la villa de Alcoi y, desde ella, el valle de Agres, más atento a la vista de la Serra de Mariola que a las propias producciones de un terreno que no acaba de ser de su agrado; camina hacia poniente, hasta encontrar Bañeres, luego gira hacia el norte, atraviesa Ontinyent, camino de Aielo de Malferit, una tierra fértil pero sometida a un sistema de impuestos insoportable para sus vecinos, lo que lleva a A.J. Cavanilles a poner en duda el derecho con el que se cobran estas recaudaciones, un tema que roza en su diario y en el que no entra en profundidad.

Desde aquí emprenderá el regreso a Valencia. En ella pondrá fin a sus diarios el día 10 de septiembre de 1793. Entonces volverá a la Corte y se dedicará a ordenar sus papeles, herbarios, dibujos y producciones minerales; del resultado de sus estudios informaría a J.C. Mutis en la primavera de 1795:

«La obra que me ocupa todos los momentos es «Observaciones sobre la historia natural, geografía, agricultura, población y frutos del reino de Valencia». Fui a recorrer aquel país hermoso, aunque lleno de montes, en los años 1791, 92, 93, por orden de Su Magestad, y a sus expensas se imprime ya la obra que saldrá en dos tomos de la misma forma que el de Icones. Tengo ya hecho y grabado el mapa general del Reino, como también otros particulares; seis láminas que representan lo que descubrí en la Marina de Calp, esto es, monumentos ocultos de una casa romana con pavimentos mosaicos; otras tres que representan las antigüedades de Cortur, el Arco romano de Cabanes y el aqueducto romano de Chelva; 28 vistas de los pueblos situados en parajes pintorescos, y otras cosillas.

71 A.J. Cavanilles, Diario de excursiones... [12-VII-1793]. (A.R.J.B., leg: XIII,7,2, p. 130). 


\section{REFLEXIONES EN TORNO A LOS VIAJES DE A.J. CAVANILLES}

Cuanto he notado en el reino vegetal y mineral, todo se explica en esta obra; en la cual doy noticia de los preciosos mármoles tan abundantes como ricos de las peñas areniscas en donde hay indicios o minas de algún metal o semi-metal. Examino el origen y curso de todas las aguas, y el partido que de ellas se saca para el riego; las calidades de tierras, las producciones que logran los colonos, las mejoras que se podrían hacer, los frutos de cada pueblo y los vecinos. No creo yo haber apurado el gran número de objetos que me propuse, pero me quedará la gloria de haber dado un modelo que otros podrán perfeccionar y seguir en las otras Provincias de España. Pues aunque mi comisión es para recorrerla toda, por desgracia no puede el rey asegurarme ni la vida ni la salud que se necesita para evacuar dignamente tan grande empresa.» ${ }^{72}$

72 Carta de A.J. Cavanilles a José Celestino Mutis. Madrid, 28-IV-1795 (transcrita en el vol. 3, p. 203-208 de la compilación realizada por G. Hernández de Alba (comp.) Archivo epistolar del sabio naturalista don José Celestino Mutis. Bogotá, 1983). 